\title{
Author Correction: Fatty acid synthesis is required for breast cancer brain metastasis
}

Gino B. Ferraro (1), Ahmed Ali, Alba Luengo (D), David P. Kodack, Amy Deik, Keene L. Abbott (1), Divya Bezwada (1), Landry Blanc (D), Brendan Prideaux, Xin Jin (1), Jessica M. Posada, Jiang Chen, Christopher R. Chin, Zohreh Amoozgar, Raphael Ferreira (D, Ivy X. Chen, Kamila Naxerova, Christopher Ng, Anna M. Westermark, Mark Duquette, Sylvie Roberge,

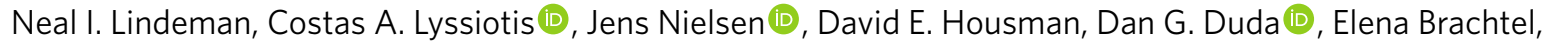

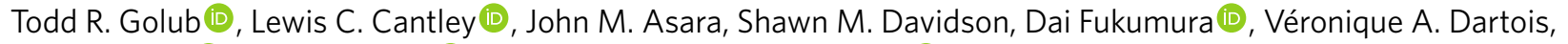
Clary B. Clish (1), Rakesh K. Jain (1) and Matthew G. Vander Heiden (D)

Correction to: Nature Cancer https://doi.org/10.1038/s43018-021-00183-y, published online 1 April 2021.

In the version of this Article initially published, there was an error in an author's name. Specifically, Jessica M. Posada's surname was mistakenly listed as "Possada." The error has been corrected in the online version of the Article

Published online: 8 October 2021

https://doi.org/10.1038/s43018-021-00283-9

(c) The Author(s), under exclusive licence to Springer Nature America, Inc. 2021 